\title{
autêntica
}

ARTIGOS

\section{FORMAÇÃO E PRÁTICAS DECOLONIAIS DE PROFESSORES FORMADORES: CONTRARIANDO O INSTITUÍDO}

\author{
Sandra Maria Nascimento de MATTOS \\ Universidade Federal Rural do Rio de Janeiro - UFRRJ \\ Seropédica, Rio de Janeiro - Brasil \\ smnmattos@gmail.com \\ https://orcid.org/0000-0003-2622-0506 \\ José Roberto Linhares de MATTOS \\ Universidade Federal Fluminense - UFF \\ Niterói, Rio de Janeiro - Brasil \\ jrlinhares@gmail.com \\ https://orcid.org/0000-0002-4075-6764
}

RESUMO: O presente artigo tem como objetivo apresentar práticas docentes decoloniais de professores formadores que transgridem o que está instituído em suas salas de aula. Essas práticas envolvem o encontro cultural com suas variadas possibilidades para promover o ensino e a aprendizagem significativa dos alunos. A formação inicial e continuada tem participação nessa modificação de olhar e influem diretamente na prática docente, quando esses professores, futuros ou atuantes, adquirem conhecimentos sobre determinadas maneiras, tais como a etnomatemática, para auxiliar a sua prática docente. É o desenvolvimento, de certa forma, da insubordinação criativa, maneiras de insurgências que contribuem para refletir sobre a estruturação da colonialidade do poder, do ser e do saber. A metodologia utilizada foi tipo etnográfica com imersão in lócus e realização de rodas de conversa, resultando em experiências enriquecedoras. A pesquisa aponta que estratégias de ensino diversificadas promovem aprendizagens mais eficazes e modificam a atuação dos professores.

PALAVRAS-CHAVE: Práticas docentes decoloniais. Professores. Ensino. 


\title{
EDUCATION AND DECOLONIAL PRACTICES OF TEACHER EDUCATORS: RESISTING THE STATUS QUO
}

\begin{abstract}
This article aims to present decolonial teaching practices of teacher educators who transgress the status quo in their classrooms. These practices involve cultural encounter with its varied possibilities to promote teaching and students' meaningful learning. Initial and continuing education participate in this change of view and directly influence teaching practices, when these teachers, pre-service and inservice ones, acquire knowledge about different ways, such as ethnomathematics, to assist their teaching practice. It is the development, in a way, of creative insubordination, ways of insurgencies that contribute to the reflection on the structuring of the coloniality of power, being and knowledge. The methodology used was an ethnographic type with immersion in locus and conversation circles, resulting in enriching experiences. The research shows that diversified teaching strategies promote more effective learning and modify teacher performance.
\end{abstract}

KEYWORDS: Decolonial teaching practices. Teachers. Teaching.

\section{FORMACIÓN Y PRÁCTICAS DECOLONIALES DE PROFESORES QUE SON FORMADORES: CONTRA LOS ESTABLECIDOS}

RESUMEN: Este artículo tiene como objetivo presentar las prácticas de enseñanza descolonial de los formadores de docentes que transgreden lo que se instituye en sus aulas. Estas prácticas involucran el encuentro cultural con sus variadas posibilidades para promover la enseñanza y el aprendizaje significativo de los estudiantes. La educación inicial y continua participa en este cambio de perspectiva e influye directamente en la práctica docente, cuando estos docentes, futuros o activos, adquieren conocimientos sobre ciertas formas, como la etnomatemática, para ayudar a su práctica docente. Es el desarrollo, en cierta forma, de la insubordinación creativa, formas de insurgencias que contribuyen a reflexionar sobre la estructuración de la colonialidad del poder, del ser y del saber. La metodología utilizada fue de tipo etnográfico con inmersión en locus y círculos de conversación, lo que resultó en experiencias enriquecedoras. La investigación muestra que estrategias de enseñanza diversificadas promueven un aprendizaje más efectivo y modifican el desempeño de los docentes.

PALABRAS-CLAVE: Prácticas de enseñanza decolonial. Maestros. Docencia. 


\section{Introdução}

Ao olharmos a dimensão política que gravita ao redor da educação brasileira, estamos no lugar de um povo que foi subjugado e que adquiriu paradigmas de outras localidades. A dominação enfraqueceu a cultura, as raízes históricas e a historicidade do povo dominado. Com isso, perdemos parte das referências e ligações afetivas que conectaríamos ao processo de dominação sociocultural e política existentes em nosso país por longos anos. A negação da historicidade começa com a invasão dos portugueses, chegando aos dias atuais com práticas abusivas dos E.U.A, interferindo em algumas políticas públicas e ações sociais. Em um país como o Brasil atual, de inspirações neoliberais, as ações e inciativas incidem sobre políticas compensatórias que não alteram as relações estabelecidas com a sociedade.

Podemos afirmar que o mesmo aconteceu e acontece com a educação brasileira, talvez com pequenas mudanças. Focando a política educacional, observamos iniciativas e ações pontuais voltadas para a gestão dos recursos financeiros; ações referentes a eficácia ou eficiência do ensino e da aprendizagem, traduzidas em avaliações de larga escala que tem seu epicentro no PISA que estabelece um ranking mundial, sem considerar as diferenças socioculturais existentes entre os países envolvidos e; da gestão escolar, aspecto que deve envolver a sociedade no que diz respeito às esferas de decisão, de planejamento e de execução da política educacional, mas que continua como oferta de serviços de favorecimento e paternalistas, quando deveria ser dever do Estado e direito da sociedade.

Atualmente, algumas instituições de ensino voltam-se para práticas que levem os professores a pensar uma pedagogia política ou uma política pedagógica que dê conta de resolver antigos problemas educacionais (MATTOS, 2020) e, ao mesmo tempo, desenvolver a leitura crítica do mundo (FREIRE, 2000) em que anunciamos ou denunciamos ações e práticas por meio de um processo de análise reflexiva do mundo. Sabemos que cada sujeito carrega suas raízes culturais (D'AMBROSIO, 2011) e quando chega à escola, sua cultura é substituída por uma outra dita escolar, segregada em disciplinas estanques que tolhe a liberdade, a criatividade, a imaginação, pois é uma cultura seletiva, hegemônica e centralizadora do pensamento, sendo a matemática a disciplina que se mantém no topo dessa pirâmide.

Diante disso, voltamos nosso olhar para práticas docentes decoloniais que promovem o encontro cultural, que valorizam e empoderam saberes e fazeres dos distintos grupos socioculturais existentes em salas de aula brasileiras, em particular, para as formas de matematizar o mundo com os outros, intercambiando conhecimentos na promoção do verdadeiro e dinâmico encontro entre as culturas. Nessa ótica, as manifestações matemáticas, mais especificamente a matemática escolar e a matemática cotidiana com seus discursos, produzem vínculos e relações de poder-saber, desfazendo um poder instituído que se mantém pelas maneiras de produzir seu discurso (WANDERER; KNIJNIK, 2008).

A pesquisa pautou-se pela abordagem tipo etnográfica, utilizando como instrumento principal o relato de experiências por meio de memorial. Tomamos como sujeitos professores formadores de professores indígenas em contexto de licenciatura intercultural e formação continuada. O objetivo foi analisar as práticas docentes desses formadores que se fazem decoloniais como caminho de insurgência, resistência e conscientização crítica a respeito dos diferentes tipos de colonialidade que estamos envolvidos. A intenção foi compreender as práticas docentes que, ao serem desenvolvidas, modificam o que está posto nas salas de aula, explicitando o fato de que o professor formador acredita no potencial dos alunos em apresentar conhecimentos para contextualizar os conteúdos matemáticos escolares. Dessa maneira, os resultados apontam para práticas 
decoloniais que alguns formadores de professores implementam em cursos de formação para discentes indígenas.

\section{O currículo almejado por intermédio de práticas decoloniais de ensino e de aprendizagem}

Alguns estudiosos, tais como Cunha (1988, 1998, 2004); Rangel (1994); Ghiraldelli Junior (1997); Freire (2003) e Lowman (2007), afirmam que "bons" professores melhoram a qualidade do ensino. Corroboramos essa ideia e cremos, também, que "bons" formadores de professores, sejam da formação inicial ou continuada, conseguem modificar comportamentos e pensamentos hegemônicos, adquiridos ao longo do processo de escolarização e do desenvolvimento inicial da prática docente. Entendemos que "bons" professores se fazem no caminhar entre o ensinar, o aprender e o possibilitar que outros aprendam. Ao mesmo tempo que o professor permite aos alunos aprenderem, ele se constitui como professor e constrói sua identidade profissional.

Quando abordamos a identidade profissional do professor, a vemos como algo que se desenvolve por meio de um processo relacional, pessoal e coletivo, que é complexa, intersubjetiva e dinâmica, evoluindo conforme o professor modifica certos comportamentos e atitudes frente ao ato de ensinar. Entretanto, devemos ter em mente que essa identidade se desenvolve em um contexto e em uma dada época. Pimenta e Anastasiou (2002, p. 189) afirmam que "a profissão do professor emerge em um dado contexto e momento histórico, tomando contornos conforme necessidades apresentadas pela sociedade, e constrói-se com base nos significados sociais que lhe são dados". E, por isso, sofre algumas causas e consequências inerentes à história pronunciada e anunciada nos currículos que são disponibilizados a esse professor, os quais geram estranhamentos para aqueles a que se destinam.

Para muitos alunos, a matemática escolar é algo que não tem sentido, tampouco algo que queiram aprender, entretanto, suportam-na por necessidade e, geralmente, são aqueles que continuam seus estudos pela necessidade de um diploma (MATTOS; ALMEIDA, 2016). Vislumbramos, assim, um fracasso estrondoso reafirmado pelos resultados obtidos no PISA. Apesar do Pisa não considerar as diferenças socioculturais dos participantes, atua como um estigma injusto, que gera sensação de fracasso e influencia aqueles que se submetem a ele. Os professores de matemática, comprometidos com o sucesso e a satisfação de seus alunos, valorizam a pesquisa no processo de ensinar. Essa pesquisa envolve o estudo da aula, estratégias de aprendizagem, a própria profissão e o entendimento sobre os alunos. Entretanto, pesquisar não é garantia para obter excelência em sala de aula, já que o professor tem que tomar certas decisões que influenciam sua atuação docente.

Pimenta e Anastasiou (2002, p. 193) ressaltam que tomar certas decisões sobre a ação docente está diretamente relacionada à posição que o professor assume, substituindo algumas iniciativas por outras, tornando-se flexível "[...] para atuar e alterar formas de ação. Exige saber ouvir, ponderar, decidir". É esse profissional que apresentaremos, ou seja, aquele que consegue modificar-se ao transformar suas ações; um professor que não enxerga sua disciplina como algo hermético, mas como possibilidades de ensinar e propiciar a aprendizagem de seus alunos; um professor que compartilha estratégias didáticopedagógicas e assume a responsabilidade de desenvolver ações diferenciadas.

Um professor, com essa expectativa, desenvolve práticas decoloniais de ensino e de aprendizagem. O termo decolonial é adotado "[...] como sendo um meio de transcender a colonialidade, ou seja, tem o objetivo de problematizar a colonialidade, refletindo sobre as condições sócio-históricas de dominação e opressão" 
(MATTOS, 2020, p. 168). Nesse sentido, entendemos que a colonialidade persiste até hoje, apregoada em quatro aspectos: colonialidade do poder, estabelecida pela cultura dominante do colonizador; colonialidade do saber, reafirmando a existência de um único conhecimento; colonialidade do ser, desumanizando membros de grupos socioculturais considerados inferiores; e colonialidade da mãe natureza, retirando as perspectivas históricas, espirituais e ancestrais de um povo (WALSH, 2008).

Cabe esclarecer que entendemos como prática docente decolonial de ensino e aprendizagem aquela que busca a justiça social, a equidade de oportunidades e intervém para que os alunos desejem aprender e desenvolvam uma aprendizagem significativa com a intenção de transcender aos aspectos da colonialidade impostos pela cultura hegemônica e opressora. Afirmamos, ainda, que se trata de construir ou reconstruir com os alunos processos de recontextualização (CONTRERAS DOMINGO, 1994) tanto dos conteúdos escolares como das estratégias com as quais esses serão apresentados, o que permite introduzir novas maneiras de olhar o conhecimento.

Nessa lógica, desenvolver práticas decoloniais de ensino e de aprendizagem é uma maneira de transgredir, de insurgir sobre o que está posto nas salas de aula, refletindo sobre as imposições advindas de paradigmas educacionais "estrangeiros" e de políticas públicas alijadas da participação coletiva dos professores e dos envolvidos com a educação em nosso país. Esses professores adotam a insubordinação criativa (D'AMBROSIO; LOPES, 2015) no rompimento da ordem estabelecida, mas não como uma maneira de causar caos, e sim por entender que a justiça social, - ou seja, ações equitativas e não somente igualitárias - , passa pelo redimensionamento da prática docente e das escolhas realizadas em sala de aula para efetivamente promover a aprendizagem dos alunos. Estamos, portanto, abordando a ensinagem (ANASTASIOU; ALVES, 2015), ou seja, a ação do professor, permeada por suas práticas, que pode realmente resultar em aprendizagem.

Para iniciar uma mudança curricular na prática docente é necessário que o professor de matemática, além de querer fazê-lo, supere inúmeras barreiras que serão impostas diante dele, tais como a administração da instituição escolar, os pares que trabalham na mesma instituição ou fora dela e o seu próprio papel nessa mudança, entre outras. O desenvolvimento de uma estrutura curricular inovadora implica em propiciar oportunidades enriquecedoras de aprendizagem e que estas sejam significativas. Assim sendo, Mattos e Mattos (2019, p. 105) ressaltam que "[...] ao abordar a matemática ou o conhecimento matemático, consideramo-lo como sendo aquele composto por diferentes matemáticas existentes no mundo", o que permite, ao professor, a utilização das maneiras existentes de matematizar a realidade nos variados grupos socioculturais.

Acreditamos que existem alguns paradigmas que interferem e até negam o desenvolvimento de uma ensinagem crítica, - entendida como a promoção da conscientização crítica e emancipação dos oprimidos na problematização os conteúdos -, pois creem no princípio da seleção de conteúdos matemáticos básicos e essenciais a serem apreendidos e, por serem lineares, hierarquizados e a-históricos, não há como inovar. Concordamos que existe, sim, uma seleção de conteúdos, mas discordamos da maneira pela qual esses conteúdos são ensinados aos alunos, ou seja, descontextualizados, fragmentados e apartados de sua realidade.

As manifestações matemáticas desenvolvidas pelos diferentes grupos socioculturais servem à aplicação, contextualizando conteúdos matemáticos escolares, mas devemos estar atentos para não criarmos uma situação demasiadamente hipotética para a elaboração de analogias entre a matemática vivida no cotidiano e matemática escolar e, assim, prejudicar a aprendizagem. Skovsmose (2000) aborda três tipos diferentes de referências para instaurar ambientes de aprendizagens com a utilização de estratégias didáticas para ensinar a matemática escolar: referência à matemática e somente a ela; referência à semirrealidade que é uma 
realidade construída; e referência à situação da vida real. Naturalmente, o professor pode mover-se nesses ambientes de aprendizagem desde que tenha segurança e não incorra em exageros.

Skovsmose (2001, p. 133) nos alerta que o professor ao desenvolver a perspectiva crítica da matemática deve mostrar aos alunos que "este corpo de conhecimentos" presente na matemática escolar é apenas uma parte das matemáticas existentes no mundo e que essa matemática é realizada por intermédio de "simplificações feitas no processo de matematização" para facilitar a apreensão dos conceitos matemáticos. Nessa lógica, práticas docentes decoloniais tomam por base os saberes e fazeres cotidianos dos alunos para alcançar resultados satisfatórios tanto para os alunos quanto para o professor. Esses resultados satisfatórios ocorrem pela atribuição de sentido e significados aos conhecimentos adquiridos e transformados, impulsionando os alunos à busca constante e permitindo-Ihes compreender que existem conhecimentos em suas práticas cotidianas.

Na elaboração de uma tarefa, o professor atenta-se para a ação que gerará nos alunos, devendo buscar os diferentes caminhos as quais a tarefa pode induzi-los, direcioná-los para a sua realização. Assim sendo, o professor cria trajetórias hipotéticas de aprendizagem com as quais pressupõe os possíveis caminhos que os alunos percorrerão e as ideias utilizadas, em uma progressão de pensamentos lógicos, para solucionar o problema proposto. Os alunos, por sua vez, aprendem que o resultado das atividades propostas é que lhes põe em ação. Dessa maneia, as tarefas não podem ser reduzidas à mecanização, decoração ou repetições sem sentido, tampouco a explicações teóricas extensas e apartada da realidade. Há que se ter equilíbrio entre o falar e o ouvir, entre o argumentar e o induzir, entre o receber e o descobrir.

O currículo que o professor de matemática desenvolve é aquele que permite aos alunos dialogarem, experienciando o fazer matemático, aprendendo a argumentar matematicamente, elaborando suas ideias a fim de alcançar a solução do problema proposto. A elaboração das estratégias didáticopedagógicas inovadoras exige preparo do professor, conhecimento do conteúdo a ser ensinado, como ensiná-lo e conhecimento sobre os alunos. A matemática escolar é reconstruída na interação com o contexto e as culturas dos alunos, partindo das incertezas momentâneas que ocorrem quando um problema cotidiano surge, levando-os a agir para alcançar uma solução.

Sendo assim, o professor que trabalha em uma perspectiva crítica da matemática escolar, que procura fazer aulas, planejando cada detalhe, primando por resultados satisfatórios e, acima de tudo, crendo no potencial de seus alunos, o faz por compreender que é preciso modificar o que está posto nas salas de aula, no que diz respeito à matemática escolar. É esse processo que práticas decoloniais alcançam, ou seja, modificam o olhar do professor de matemática tanto a respeito de sua prática docente como de sua formação profissional. Percebemos que o uso da etnomatemática, tida como uma metodologia que se abre à geração e difusão do conhecimento como produção dos variados grupos socioculturais, possibilita o trabalho mental, levando a uma postura interferente no mundo (MATTOS, 2020).

D'Ambrosio (2011, p. 17) afirma que a etnomatemática procura "entender o saber/fazer matemático ao Iongo da história da humanidade, contextualizado em diferentes grupos de interesse, comunidades, povos e nações". Assim sendo, a utilização da etnomatemática possibilita aliar culturas diferentes, contextualizar conteúdos matemáticos escolares com o cotidiano dos alunos e induz a prática interdisciplinar constante, já que os conhecimentos se constituem em um conjunto harmonioso, nunca fragmentado, que beira a transdisciplinaridade. A etnomatemática praticada decolonialmente religa saberes e fazeres que se fundam nos conhecimentos acumulados pela humanidade ao longo dos tempos. 


\section{Formadores de professores indígenas: práticas docentes que contrariam o instituído}

DOI https://doi.org/10.31639/rbpfp.v13i26.334

Em nossas pesquisas nos deparamos com alguns formadores de professores indígenas e, em conversas, percebemos a importância dessa modificação de olhar sobre a prática docente. Ressaltamos que a licenciatura intercultural indígena é uma graduação realizada especificamente para os povos indígenas, surgida da necessidade desses povos de assegurar, em suas escolas, um corpo docente constituído por professores indígenas, já que a educação escolar indígena deve ser diferenciada, intercultural, bilingue e comunitária, aspectos assegurados pela Lei de Diretrizes e Bases da Educação Nacional - LDBEN 9394/96 (BRASIL, 1996), pelo Referencial Curricular Nacional de Educação Indígena - RCNEl/98 (BRASIL, 1998), bem como pela Resolução CEB nº 3 de 1999 (BRASIL, 1999).

O Programa de Apoio à Formação Superior e Licenciaturas Interculturais Indígenas - Prolind, em consonância com edital $n^{\circ} 5$ de 2005, convoca as instituições de ensino superior (IES) para a criação de licenciaturas interculturais indígenas com o objetivo de "instituir um programa integrado de apoio à formação superior indígena, em especial à formação de professores indígenas, como uma política de estado a ser implementada pelas IES públicas de todo o país" (BRASIL, 2005, p. 1). O Prolind subdivide-se em três eixos de apoio: projetos que já existiam para formação de professores indígenas; projetos e articulações que reuniam professores indígenas e instituições para formação superior de professores indígenas e as universidades que utilizam cotas ou reservas de vagas para os povos indígenas em seu processo seletivo.

O eixo central do Prolind é implementar e fortalecer cursos de formação de professores indígenas em nível superior, promover a permanência dos estudantes indígenas em salas de aula em constante interação com as aldeias e desenvolver estratégias decoloniais de ensino, ou seja, que levem à construção coletiva do conhecimento e que facilitem o aprendizado dos conhecimentos científicos, que os auxiliarão a tornarem-se professores qualificados para a promoção de uma educação escolar indígena que fortaleça sua cultura, sua língua e traços ancestrais, empoderando-os e reafirmando a identidade indígena. Nessa lógica, cabe às IES estabelecer diálogo ou propiciar mecanismos institucionais de diálogo com os povos indígenas, fortalecendo laços e criando pontes de formação inicial e continuada.

Essas especificidades asseguram a história de cada povo indígena, sua língua, sua cultura e identidade. A maioria dos indígenas que procuram a licenciatura intercultural relatam a necessidade de uma formação que atenda as características locais de seu povo e que possibilite uma prática docente que adeque os conteúdos escolares às especificidades indígenas. Consequentemente, essa graduação tem que ser diferenciada, estabelecida por um currículo inovador, com metodologias diversificadas para que os indígenas adquiram os domínios dos conhecimentos necessários. Assim, a licenciatura intercultural indígena desenvolve-se em quatro áreas: Matemática e Ciências da Natureza; Pedagogia; Línguas, Artes e Literaturas e Ciências Sociais.

Nessa perspectiva, os formadores de professores indígenas têm que considerar essas especificidades e articular os saberes e fazeres indígenas com os conhecimentos científicos, desenvolvendo atividades didáticopedagógicas que propiciem a reflexão sobre a aquisição de alguns conhecimentos para o fortalecimento da cultura de cada povo. Para reforçar essa ideia, recorremos a Gimeno Sacristán (2000, p. 46) quando afirma que o currículo deve "[...]dar lugar à criação de experiências apropriadas que tenham efeitos cumulativos [...]". O currículo por ser uma tarefa prática, muitas vezes, prescreve os resultados que o ensino deve promover, mas o professor crítico atua em uma perspectiva dialética teoria-prática em que a teoria se alia ao suporte cultural para contextualizar e dinamizar a prática. 
Em nossas pesquisas, dialogamos com alguns professores indígenas e formadores de professores indígenas. Relataremos, inicialmente, o trabalho com um professor formador de professores da licenciatura intercultural indígena da Unifap que, utilizando a etnomatemática para o ensino de conceitos matemáticos escolares, evidenciou aspectos culturais dos indígenas, levando-os a refletir e relacionar saberes e fazeres do cotidiano indígena para mediar sua prática docente. Em uma das tarefas propostas, o professor teve a intenção de assumir a experiência formativa dos alunos que já atuavam como professores indígenas, que era mediada pela cultura, retratando seus modos de vida, suas características, apresentados em seus saberes e fazeres cotidianos da aldeia.

Nessa ótica, os alunos indígenas foram estimulados a verificar o papel dos conhecimentos matemáticos oriundos do cotidiano da aldeia e a identificar noções e ideias matemáticas escolares que emergem dessa cultura, segundo a concepção deles. Sobre essa experiência, o professor nos relatou que:

Um fato importante que meu processo de formação e autoformação tem evidenciado é a busca por desconstruir o caráter hegemônico da Matemática escolar/acadêmica forjada pelo currículo, quer seja pelas políticas educacionais ou pelos livros. Acredito que é no contexto da própria prática, para além do que é proposto e imposto, que tenho ousado a fazer diferente. (Professor formador).

Assim sendo, a partir dos estímulos por ele lançados, os alunos refletiram e argumentaram sobre o que pensavam a respeito da matemática, independente de qual das manifestações matemáticas. Como suporte ao estímulo, os alunos deveriam produzir um texto, dar um título e ilustrar com desenhos. Vários conceitos matemáticos escolares vieram à tona nas produções dos futuros professores, alguns relacionados à geometria, outros ao sistema de medidas e mais alguns aos grafismos e formas geométricas, entre outros. Com essa atividade o professor ressaltou reconhecer que "não é tão fácil se desvencilhar de todos os paradigmas a que estou imerso, mas é um exercício que tenho feito tendo em vista complementar as aplicações entre os conhecimentos" (Professor formador, 2020).

Alguns trabalhos apresentaram a confecção e utilização de artefatos indígenas, tais como a peneira e o paneiro, que é um cesto para colocar frutas e outros objetos. Está relacionado, ainda, às medidas por eles utilizadas diariamente. Um dos trabalhos apresentou a produção de farinha, descrevendo em detalhes as quantidades utilizadas para a produção. Outro trabalho apresentou a confecção da cuia e os grafismos que são realizados nela, bem como seus significados na cultura indígena de seu povo. Em seu relato o professor afirma que:

Compreendo que os conhecimentos são, por vezes, incomensuráveis, visto que não podem ser traduzidos simplesmente um pelo outro sem a relevância dos seus contextos. Ainda que, em determinadas disciplinas da formação docente em Matemática, os conhecimentos científicos e os conhecimentos próprios tenham suas racionalidades, pensar e refletir a partir do Programa Etnomatemática tem suscitado minhas formas de ensinar, a escolha dos conteúdos a serem ensinado, as minhas formas de avaliar, que se diferenciam de turma para turma, com as especificidades dos sujeitos (Professor formador).

Cabe ressaltar que o curso contava com alunos de diferentes etnias do Oiapoque; cada qual buscou na sua cultura formas de ensinar a matemática escolar de maneira que articulasse a vivência cotidiana da aldeia. Afirmamos que esse professor formador, no desenvolvimento dessa tarefa, possibilitou aos futuros professores indígenas ou para aqueles que já atuam, um novo olhar para a cultura deles. Em sua análise, após o término dessa prática, o professor formador relatou que: 
O sentido dessa prática formativa foi mostrar aos professores indígenas que os conhecimentos matemáticos de suas culturas podem ser mobilizados em suas práticas pedagógicas. Vejo como uma escolha metodológica e epistemológica, tendo em vista que o ensino nas escolas indígenas possa dar sentido aos conteúdos a partir dos artefatos, das práticas e dos saberes que são praticados na lida com o cotidiano da aldeia (Professor formador).

Essa experiência formativa facilitou a produção de modos de ensinar a matemática escolar, partindo de significados socioculturais indígenas. Além disso, possibilitou o fortalecimento da identidade da etnia e os empoderou no que diz respeito aos seus saberes e fazeres tradicionais. De acordo com Bicho e Mattos (2018, p. 81), experiências formativas desse tipo revelam "[...] possíveis diálogos entre saberes matemáticos escolares e saberes tradicionais expressos por professores indígenas em formação inicial". Os autores ainda ressaltam que "a cultura é evidenciada como experiência formativa de professores indígenas no que tange aos diálogos entre os diferentes modos de fazer matemática [...]". Portanto, a formação inicial deve fortalecer as próprias características indígenas, apresentada em sua cultura, para desenvolver estratégias educativas de ensino e de aprendizagem.

Outra experiência que relataremos é de um professor formador indígena da etnia Paiter Suruí que atua no Projeto Açaí de Rondônia. Esse projeto foi criado por meio do decreto estadual $n^{\circ} 8516$, de 15 de outubro de 1998 (RONDÔNIA, 1998), instituindo o Curso de Formação de Professores Indígenas - Habilitação em Magistério em Nível Médio, com o objetivo de habilitar exclusivamente docentes indígenas leigos que atuam nas escolas localizadas em terras indígenas de Rondônia e que lecionem para os cinco primeiros anos do ensino fundamental. Esse professor formador atuou nos módulos VIII, IX e X, convidado pela Secretaria de Estado da Educação - SEDUC de Rondônia e pelo Núcleo de Educação Escolar Indígena - NEEl, para lecionar a disciplina de língua materna.

Nesses módulos, o professor formador indígena lecionou para 160 alunos indígenas, divididos em quatro turmas que eram constituídas por diferentes etnias de Rondônia. Segundo o professor formador indígena nos relatou, participavam 26 etnias:

No Projeto Açaí havia 160 alunos indígenas de Rondônia matriculados, sendo dividida em quatro turmas de vários etnias de Rondônia, como: Paiter Surui, Cinta-larga, Mamaidê, Aikanã, Latunde, Gavião, Arara Karo, Tupari, Makurap, Aruá, Arikapú, Migueleno, Puruburá, Djeorometxi (jabuti), Oro não, Oro waram xijen, Orowaje, Oro Wim, Oro at, Oro mom, Canoé, Oro eo, Oro..., karitiana, kaxarari, Uru eu wau wau e Amondawa (Professor formador indígena).

Suas aulas eram planejadas para atender as diferentes etnias e ele esforçava-se para, com sua prática didática em língua materna de sua etnia, atender de forma geral todos os alunos que estavam em sala de aula. Nessa perspectiva, o professor formador indígena procurou explorar temas que envolvessem a oralidade, a escrita, neologismos indígenas, a língua como forma de resistência, empréstimos linguísticos, língua portuguesa nas escolas indígenas, entre outros temas. Em seu relato, ele afirma que:

O trabalho de língua materna, a metodologia, tenho que planejar muito para privilegiar a etnia existente na sala. O tema do primeiro dia de aula para turma A foi "Importância da oralidade e escrita para povos indígena e Neologismo indígena" com 16 hs trabalhada para cada turma. Este trabalho foi para Paiter Surui, mas para etnias diferentes, por isso o planejamento foi bem preparada para que o trabalho seja transparente na realidade de cada povo. No modulo IX, o tema foi Línguas indígenas e a sua colonização e resistência, Criação de novos vocábulos a partir da própria língua 


\begin{abstract}
e empréstimos linguísticos com a devida adaptação fonológico. No módulo X, o tema foi sobre a preservação/transmissão das línguas indígenas e Língua portuguesa, Língua indígena, Língua portuguesa nas escolas indígenas e o que aprender e como ensinar? Modelo de trabalho do professor indígena na escola (Professor formador indígena).
\end{abstract}

Como podemos observar, há um esforço para sanar dificuldades tanto na abordagem da língua materna como da língua portuguesa e nas maneiras de lecionar essas disciplinas para os alunos indígenas dos anos iniciais, sempre voltadas para o empoderamento e para ao fortalecimento da identidade de cada etnia. Em sua prática docente decolonial, ele entende que "resistir é perceber pequenos atos que nos incomodam. É anunciar ou denunciar. É fazer que nossa fala se reverta em nossa prática" (MATTOS, 2020, p. 170). Dessa maneira, o professor formador problematiza as dificuldades para o ensino e a aprendizagem da língua materna e do português e lança questões instigantes, aos alunos, para que possam refletir e buscar suas próprias soluções dentro da sua etnia.

Assim sendo, o professor formador nos relatou que sempre se dedica e que busca a melhor estratégia didática para alcançar as diferentes etnias que compõem cada turma. Afirma, ainda, que em cada aula surpreende-se e é surpreendido pelos alunos. De acordo com ele:

Minha contribuição de experiência no projeto Açaí, foi tão compensador para os professores indígenas levarem esse conhecimento, ou seja, aprendizagem para suas escolas. Minha participação sendo como professor indígena foi muito importante de ensinar os professores de alfabetização na língua materna. Fui primeiro professor indígena de Língua materna no AÇAí, isso me fez sentir no momento de aula o que eu sou, me tornei grande professor perante meus alunos (Professor formador indígena).

O entusiasmo desse professor formador indígena nos faz acreditar que práticas decoloniais possibilitam experiências enriquecedoras em sala de aula e que devemos fazer aulas como uma estratégia para resistir ao que nos é imposto. Ainda mais, quando praticamos a insubordinação criativa, pois estamos construindo caminhos prazerosos e fecundos para nossos alunos. 


\section{Considerações finais}

As práticas docentes que apresentamos constituem um pequeno recorte de uma pesquisa com inúmeros professores que buscam fazer com que suas aulas transgridam o instituído e possibilitem um olhar reflexivo sobre aquilo que disponibilizamos aos nossos alunos; que entendem que o que ensinamos, por intermédio dos saberes e fazeres trazidos pelos alunos, descortinam variadas possibilidades de diálogo, de troca e de inter-relações entre o professor, os alunos e o conhecimento. Nessa ótica, esses professores formadores buscaram afetar seus alunos, isto é, intensificaram a mediação cognitiva-afetiva em sala de aula e assim buscaram promover a aprendizagem significativa de seus alunos.

Ressaltamos que o currículo desenvolvido pelos professores não foi um mero apresentar o que está escrito e prescrito em manuais e livros didáticos, mas foi um fazer conjunto, em que os alunos elaboram seus pensamentos sobre um conhecimento e juntos, professor e alunos, reconstroem esse conhecimento, adequando-o à realidade em que estão imersos, na qual irão atuar. A necessidade de possibilitar aos alunos oportunidades de argumentar, refletir e criar é um processo contínuo, que requer análise crítica por parte do professor, mas que se torna enriquecedor para ambos. Envolver diferentes culturas em torno de um tema mobiliza o ensino para práticas docentes decoloniais e capacita os alunos buscarem respostas na realidade da qual participam.

Quando os professores formadores deparam-se com alunos tão diversificados, com tanta riqueza de experiências em suas práticas cotidianas, é imprescindível permitir que estas adentrem a sala de aula e favoreçam o desenvolvimento de um discurso decolonial, combatendo a colonialidade do saber, que aniquila os conhecimentos tradicionais de diferentes grupos socioculturais, a colonialidade do ser, que desumaniza os sujeitos considerados inferiores frente a uma sociedade hegemônica e seletiva; a colonialidade do poder, que massacra os desvalidos e subjuga sua identidade e sua cultura e, por fim, a colonialidade da mãe natureza, que impõe um tipo de tratar o ambiente e de desenvolver a espiritualidade, pondo fim ao que está fora dos padrões pré-estabelecidos pelos dominadores.

É esse tipo de aula que fomos encontrar nas salas de aula dos diferentes formadores pesquisados. É uma estratégia de insurgência que promove tanto a aprendizagem dos alunos como a reflexão crítica sobre aquilo que se ensina, sobre o que nos é imposto e proposto como viável aos alunos para que tomem conhecimento; não estabelecendo uma forma ou outra de ensinar, mas propiciando um ensino que possa realmente resultar em aprendizagem, visto que uma estratégia decolonial e libertadora pressupõe um projeto (DUSSEL, 2016), no qual os licenciandos valorizem suas culturas e, a partir delas, tornem-se críticos e reflexivos sobre elas. Além disso, traga felicidade tanto para o professor como para os alunos. Ao satisfazer sua finalidade de ensinar, o professor também satisfaz o propósito dos alunos que é aprender. Dessa maneira, a prática docente decolonial foca os aspectos éticos, críticos e reflexivos a respeito do ensino e da aprendizagem e envolve alternativas docentes que atendam as expectativas dos alunos quando buscam um curso de formação, seja inicial ou continuada. 


\section{REFERÊNCIAS}

ANASTASIOU, Léa G. C.; ALVES, Leonir P. Processos de ensinagem na universidade: pressupostos para as estratégias de trabalho em aula. 10. ed. Santa Catarina: Univille, 2015.

BICHO, José S.; MATTOS, José R. L. Formação de professores indígenas: diálogos entre saberes sob a ótica da etnomatemática. In: MATTOS, Sandra M. N. (org). Currículo, formação e práticas docentes. Curitiba: CRV, 2018. p. 61-84.

BRASIL. Programa de Apoio à Formação Superior e Licenciaturas Indígenas - PROLIND. Edital de convocação n 5, de 29 de junho de 2005. Brasília: MEC, 2005.

BRASIL. Resolução CEB n 3, de 10 de novembro de 1999. Fixa Diretrizes Nacionais para o funcionamento das escolas indígenas e dá outras providências. Brasília: MEC, 1999.

BRASIL. Referencial Curricular nacional para as escolas indígenas. Brasília: MEC, 1998.

BRASIL. Lei de Diretrizes e Bases da Educação Nacional. Lei n 9.394, de 20 de dezembro de 1996. Estabelece as diretrizes e bases da educação nacional. Brasília: MEC, 1996.

CONTRERAS DOMINGO, José. Enseñanza, Curriculum y Profesorado: introducción crítica a la didáctica. 2. ed. Madrid: Akal, 1994.

CUNHA, Maria I. A relação professor-aluno. In: VEIGA, IIma P.A. (coord.). Repensando a didática. 21. ed. rev. e atual. SP: Papirus, 2004, p. 149-159.

CUNHA, Maria I. O bom professor e sua prática. Rio de Janeiro: Papirus, 1998.

CUNHA, Maria I. A prática pedagógica do "bom professor": influências na sua atuação. 1988. Tese. (Doutorado em Educação). UNICAMP - Faculdade de Educação, Campinas, 1988. Disponível em: <http://www.repositorio.unicamp.br/handle/REPOSIP/251104>. Acesso em 27 dez. 2012.

D,AMBROSIO, Beatriz S.; LOPES, Celi E. Insubordinação criativa: um convite à reinvenção do educador matemático. Bolema, v. 29, n. 51, p. 1-17, 2015. Disponível em <http://www.scielo.br/pdf/bolema/v29n51/1980-4415-bolema-29-51-0001.pdf>. Acesso em 16 jan 2019.

D'AMBROSIO, Ubiratan. Etnomatemática - elo entre as tradições e a modernidade. 4.ed. Belo Horizonte: Autêntica Editora, 2011.

DUSSEL, Enrique. Transmodernidade e interculturalidade: interpretação a partir da filosofia da libertação. Revista Sociedade e Estado, vol. 31, n. 1, p. 51-73, 2016. Disponível em https://www.scielo.br/pdf/se/ v31n1/0102-6992-se-31-01-00051.pdf. Acesso em 16 jan 2019.

FREIRE, Paulo. Pedagogia da autonomia: saberes necessários à prática educativa. 28. ed. São Paulo: Paz e Terra, 2003.

FREIRE, Paulo. Pedagogia da indignação: cartas pedagógicas e outros escritos. São Paulo: UNESP, 2000. 
GIMENO SACRISTÁN, José. O currículo: uma reflexão sobre a prática. Trad. Ernani F. da F. Rosa. 3. ed. Porto Alegra: Artmed, 2000.

GHIRALDELLI JUNIOR, Paulo. O que é um "bom professor" ? O professor no discurso pedagógico no mundo moderno e contemporâneo. Educação e Filosofia. v. 1, n. 21 e 22, p. 245-262, 1997. Disponível em: <http:// www.seer.ufu.br/index.php/EducacaoFilosofia/article/view/895 >. Acesso em 06 jan 2013.

LOWMAN, JOSEPH. Dominando as técnicas de ensino. Trad. Harue Ohara Avritscher. Cons. Téc. Ilan Avrichir, Marcos Amatucci. São Paulo: Atlas, 2007.

MATTOS, Sandra M. N. O sentido da matemática e a matemática do sentido: aproximações com o programa etnomatemática. São Paulo: Livraria da Física, 2020.

MATTOS, Sandra M. N.; MATTOS, José R. L. Etnomatemática e prática docente indígena: a cultura como eixo integrador. Hipátia, v. 4, n. 1, p. 102-115, 2019. Disponível em <https://ojs.ifsp.edu.br/index.php/hipatia/ article/view/1092/809>. Acesso em 12 jun 2019.

MATTOS, Sandra M. N.; ALMEIDA, Laurinda R. Sentimentos expressos por alunos do ensino fundamental II: a aula de matemática em foco. In: ENCONTRO NACIONAL DE EDUCAÇÃO MATEMÁTICA, 12, 2016, São Paulo, Anais [...]. São Paulo, Universidade Cruzeiro de Sul, 2016. p. 1-12.

PIMENTA, Selma G.; ANASTASIOU, Léa G. C. Docência no ensino superior. São Paulo: Cortez, 2002. [Coleção Docência em formação, v. 1].

RANGEL, Mary. Representações e reflexões sobre o bom professor. 7. ed. Rio de Janeiro: Vozes, 1994.

RONDÔNIA. Lei no 8516 de 15 de outubro de 1998. Institui o Curso de Formação de Professores Indígenas Habilitação em Magistério Nível Média, denominado PROJETO AÇAí, e dá outras providências. Rondônia, 1998.

SKOVSMOSE, Ole. Educação matemática crítica: a questão da democracia. São Paulo: Papirus, 2001. [Coleção Perspectiva em educação matemática].

SKOVSMOSE, Ole. Cenários de investigação. Bolema, v. 13, n. 14, p. 66-91, 2000. Disponível em <http:// www.periodicos.rc.biblioteca.unesp.br/index.php/bolema/article/view/10635>. Acesso em 16 abr 2014.

WALSH, Catherine. Intercultuaridad, plurinacionalidad y decolonialidade: las insurgências político-epistémicas de refundar el Estado. Tabula Rasa. Bogotá - Colômbia, n. 9, p. 131-152, 2008. Disponível em <http://www. scielo.org.co/pdf/tara/n9/n9a09.pdf >. Acesso em 06 jul 2019.

WANDERER, Fernanda; KNIJNIK, Gelsa. Discursos produzidos por colonos do sul do país sobre a matemática e a escola do seu tempo. Revista Brasileira de Educação, v. 13, n. 39, p. 555-564, 2008. Disponível em <http://www.scielo.br/pdf/rbedu/v13n39/11.pdf>. Acesso em 23 set 2019. 
